\title{
Esferas de ATIVIDAde SIMBólica e A CONSTRUÇÃo de CONHECIMENTO PELA CRIANÇA SURDA ${ }^{1}$
}

\author{
SPHERES OF SYMBOLIC ACTIVITY AND DEAF CHILDREN'S CONSTRUCTION OF \\ KNOWLEDGE
}

\author{
Claudia Campos Machado ARAÚJO² \\ Cristina Broglia Feitosa de LACERDA ${ }^{3}$
}

\begin{abstract}
RESUM O : este estudo ancora-se na abordagem bilíngüe para explorar e abordar as esferas simbólicas da linguagem - gesto, desenho, narrativa e escrita - concomitante à língua de sinais no desenvolvimento de linguagem da criança surda e na construção de novos conhecimentos. A partir do referencial de análise qualitativa foram utilizados os construtos teóricos e metodológicos da perspectiva Histórico-Cultural e de sua articulação com a análise microgenética. Os sujeitos da pesquisa foram duas crianças surdas bilíngües, em fase de aquisição tanto da língua de sinais, quanto da escrita da língua portuguesa, cursando a 2ª série do Ensino Fundamental. A mbas eram do sexo masculino, na faixa etária de 9 e 10 anos, e diagnóstico audiológico de surdez profunda bilateral. O foco das análises privilegiou a emergência dos processos em mudança na dinâmica das interações entre os sujeitos que participaram da pesquisa, considerando o aspecto particular e global na sua ocorrência e constituição. As atividades simbólicas favoreceram a ampliação da língua de sinais e acessos iniciais à escrita, abrindo espaço para a consolidação de signos e para o desenvolvimento de linguagem. O uso prioritário da língua de sinais, associado ao trabalho com atividades sígnicas, além da consideração das particularidades lingüísticas e das mediações semióticas, foram fundamentais para o desenvolvimento da linguagem da criança surda e para a construção de conhecimentos, de maneira satisfatória e adequada à sua constituição como sujeito ativo e participante da linguagem.
\end{abstract}

PALA V RA S-CHAVE: linguagem; desenho infantil; escrita; bilingüismo; surdez; educação especial.

ABSTRACT: this study is grounded on a bilingual approach and it aims to explore and to approach the symbolic spheres of language - gesture, drawing, narrative and writing - concomitantly to sign language in deaf children's language development and to the building of new knowledge. Theoretical and methodological constructs stemming from the Historic-Cultural perspective and its articulation with the microgenetic analysis were used in this qualitative analysis. Research subjects were two deaf boys who were in the process of bilingual language acquisition - Brazilian sign language and the written modality of Brazilian Portuguese; both were in the second grade of Brazilian elementary education level, with ages between 9 and 10 years and both had audiological diagnoses of profound bilateral deafness. The focus of the analysis highlighted the emergence of changing processes in the dynamics of interactions between the research subjects, taking into account the particular and global aspects in their occurrence and constitution. Symbolic activities enable the broadening of sign language and beginning access to writing, which in turn promote the

\footnotetext{
${ }^{1}$ Este artigo é parte da Tese de Doutorado intitulada "Linguagem e desenho infantil: aspectos do desenvolvimento simbólico da criança surda e implicações terapêuticas", com financiamento da Coordenação de A perfeiçoamento Pessoal de Nível Superior - Capes.

${ }^{2}$ Fonoaudióloga. Doutora em Saúde da Criança e do Adolescente da Faculdade de Ciências Médicas da Universidade Estadual de Campinas - SCA/ FCM/ Unicamp - claudia-araujo@uol.com.br

${ }^{3}$ Fonoaudióloga. Doutora em Educação pela Universidade Estadual de Campinas. Docente do Curso de Fonoaudiologia e do Programa de Pós-Graduação em Educação da Universidade M etodista de Piracicaba. Pós-doutorado no CNR-Itália - clacerda@unimep.br
} 
consolidation of signing and language development. The priority given to sign language use associated with working with semiotic activities which take into account linguistic particularities and semiotic mediations were vital for language development of these deaf children and for the construction of knowledge, in a way that is both satisfactory and adequate to their constitution as active subjects and participants in language.

KEYWORDS: language; children's drawing; writing; bilingualism; deafness; special education

\section{InTRODUÇÃo}

Os profissionais da área da saúde e da educação, envolvidos no trabalho com surdos, visam à otimização da comunicação e melhor integração social desses sujeitos. Para isso, é necessário que a família (primeiro grupo responsável pela criança) seja orientada e informada a respeito do significado da surdez, de suas conseqüências para a comunicação infantil e da aquisição fundamental da Língua Brasileira de Sinais (Libras) como primeira língua, que será capaz de garantir o desenvolvimento cognitivo e lingüístico para a melhor inserção da criança na sociedade (GUARINELLO; LACERDA, 2007).

Mas, apesar da importância de favorecer e iniciar o desenvolvimento da língua de sinais a partir do diagnóstico, grande parte dos surdos é exposta inicialmente apenas à linguagem oral, acarretando um relevante atraso de linguagem e conseqüente prejuízo no processo de significação. É neste contexto, com dificul dades para o desenvolvimento de uma língua oral, apoiada em aspectos oral-auditivos (língua dos pais ouvintes), e sem uma língua estruturada, apoiada em aspectos viso-espaciais (língua da comunidade surda) que a criança surda chega, freqüentemente, à escola, convidada a constituir-se leitora/ escritora de uma língua que não domina.

A Clínica Fonoaudiológica tem sido ao longo do tempo grande responsável por estes casos, já que majoritariamente, focal iza sua atenção para a protetização e o trabal ho para o desenvolvimento de língua oral . A penas quando este modelo não alcança os resultados esperados, o que é freqüente, recorre tardiamente à língua de sinais.

Todavia, a partir da década de 1990, alguns fonoaudiólogos (LACERDA et al., 2000) mais atentos ao desenvolvimento de linguagem de sujeitos surdos, têm trabalhado em uma perspectiva bilíngüe (língua de sinais/ português escrito e quando possível, oral) buscando inserir o mais rapidamente possível estes sujeitos no mundo da linguagem.

Há que se considerar que a criança surda não pode construir a modalidade escrita da língua majoritária à qual está submetida pela via da oralidade, ou correlacionando aspectos da oralidade com outros da escrita. A criança surda percorre caminhos próprios, uma vez que deve aprender a escrever uma língua que ela, em geral, não fala e não domina (FERNANDES, 2006). 
Sendo este um grande desafio, é necessário então, pensar em uma prática clínica e educacional, aberta, criativa, que junto ao sujeito surdo, propicie que este se constitua como sujeito da linguagem, desenvolvendo e construindo novos conhecimentos de maneira satisfatória e adequada às suas condições lingüísticas.

No caso das crianças que não tiveram a oportunidade de desenvolver a Libras, torna-se necessário que o trabalho fonoaudiológico eeducacional, dentro de uma abordagem bilíngüe, seja orientado para o conhecimento, valorização e apropriação desta língua, sobre a qual elas poderão refletir e construir os significados de uma segunda língua, no caso, a escrita do português (LODI, 2000). $E$, ainda, os processos terapêuticos e pedagógicos devem ser permeados por situações em que práticas sociais de leitura e escrita estejam presentes, ainda que o próprio paciente nada leia ou escreva, na busca de inseri-lo em práticas de letramento (MASINI, 2004).

Fundamentado na teoria Histórico-Cultural este estudo pretende discutir e explorar a relação e inter-relação das atividades simbólicas (gesto, desenho, narrativa, escrita e língua de sinais) que podem favorecer o desenvolvimento da linguagem de crianças surdas, usuárias tardias da Libras, e em fase de aquisição da escrita da Língua Portuguesa.

A partir da teoria Histórico-Cultural sobre a concepção de desenvolvimento e de conhecimento humano, Vigotski (1998) ${ }^{4}$ afirma que as atividades mentais da criança são organizadas e desenvolvidas na complexidade de suas múltiplas interações, mediada pelo outro e pelo signo.

Os indivíduos de uma mesma cultura partilham de uma língua que permite a compreensão e a interação entre si. As palavras, que são os signos constitutivos de uma língua, têm um significado comum, quase sempre, para estes sujeitos. Pela relação com a palavra a atividade mental da criança se constitui. É por essa relação que ela conhece sua cultura e tem consciência de seu mundo significativo e categorial.

A linguagem apresenta-seà criança na intersubjetividade, em relações partilhadas com outras crianças e com adultos do seu meio sócio-cultural. Por ser um dos primeiros sistemas de signos que a criança utiliza, a linguagem - que ocupa papel central na teoria H istórico-Cultural - é vista como elemento essencial de mediação na construção e no desenvolvimento de conhecimentos e de atividades representativas, portanto, atividades simbólicas que envolvem significados e sentidos.

\footnotetext{
${ }^{4}$ Usaremos a grafia Vigotski neste texto já que seu nome tem sido grafado de diferentes maneiras segundo as diferentes línguas para as quais é traduzido. E, nas referências bibliográficas, será adotada a grafia do nome conforme original.
} 
A pontando as bases para a compreensão do simbólico, Vigotski (1934/2005)5 afirma que os signos são os mediadores das relações entre os homens, que o uso de signos marca o ser social dos indivíduos e quea linguagem éo signo por excelência e principal mediador necessariamente simbólico entre o mundo cultural e o biológico. O caráter semiótico do desenvolvimento humano refere-se à atividade específica da linguagem, que providencia os instrumentos auxiliares para a solução dos problemas, direciona a vontade, planeja a ação, controla e regula o comportamento. As ações humanas, mais do que ações condicionadas por estímulos externos, são ações mediadas por signos.

Falar então do desenvolvimento do processo de simbolização implica falar de desenvolvimento do processo de operação com signos. Explicando este processo, Vigotski (1998, p. 51) diz que: "a criança não deduz, de forma súbita e irrevogável, a relação entreo signo eo método deusá-lo". A atividadedeutilização de signos surge em um processo de desenvolvimento de operações nas quais ocorrem transformações qualitativas.

Sendo a forma psicológica principal de comunicação social e constituidora da consciência humana, a linguagem está também atrelada ao processo gráfico. Vigotski afirma que a linguagem escrita é um sistema particular desímbolos, cujo domínio prenuncia um ponto crítico em todo o desenvol vimento cultural da criança, por meio deum longo processo dedesenvolvimento de funções comportamentais complexas (percepção, memória e solução de problemas) e da compreensão de toda a história do desenvolvimento - movimento progressivo dos signos na criança. N este processo histórico e unificado de desenvolvimento, o gesto é o signo visual inicial que contém a futura escrita da criança: "os gestos são a escrita no ar, e os signos escritos são, freqüentemente, simples gestos que foram fixados" (VIGOTSKI, 1998, p. 142).

Freqüentemente, as crianças usam a dramatização, demonstrando por gestos, o que gostariam de mostrar nos desenhos, isto é, os primei ros rabiscos constituem somente um suplemento à representação gestual. Posteriormente, ao desenhar conceitos complexos ou abstratos, novamente as crianças indicam as qualidades que conhecem do objeto, e o lápis meramente fixa o gesto indicativo.

Considerando-sequeo gesto éa "possibilidadedeparticipar das ações, como expressão da vontade, companheiro da palavra, modo de sefazer entender" (PADILHA, 2000, p. 215), esta fase do desenvolvimento do grafismo coincide com todo o aparato motor geral infantil e que governa a natureza e o estilo dos seus primeiros desenhos.

\footnotetext{
${ }^{5}$ Quando a referência da obra aparecer ano/ ano, a primeira data corresponde à publicação do original, e a segunda, à da tradução consultada.
} 
Posteriormente, a partir do que é significado socialmente por adultos ou pares que interagem com ela, a criança começa a dar origem a formas de grafismo, e os gestos cumprem uma função de substituição, ou seja, os simples sinais indicativos e traços e rabiscos passam à representação pictográfica, que começam a designar simbolicamente algum objeto.

Deacordo com Ferreira (1998), a partir do momento em queo desenho é figurativo e pode ser interpretado como representação da realidade, referindose a elementos ausentes do espaço e do tempo presentes, ele torna-se signo: o que caracteriza o signo é o fato del eser interpretável. É a interpretação que transforma uma figuração em signo.

Se a figuração simboliza, ou seja, se traz implicados significados e sentidos, esta possibilidade está imprescindivelmente articulada à palavra: a figuração no desenho é dotada de significado, que é refletida pela linguagem. Desta forma, no processo gráfico, os significados das figurações do desenho da criança são culturais e produto das suas experiências com os objetos reais, mediados pela palavra e pela interação com o outro.

Como linguagem gráfica, também do desenho decorre a linguagem escrita. Encontra-se em Vigotski (1998, p. 127) que: “o desenho é uma linguagem gráfica que surge tendo por base a linguagem verbal" e pode ser considerado "um estágio preliminar no desenvolvimento da linguagem escrita".

No desenvolvimento deste simbolismo, a criança percebe que pode desenhar não só objetos, mas também palavras. Vigotski (1998) considera que o desenvolvimento da linguagem escrita na criança está neste deslocamento. Esta transição deve ser propiciada à criança de maneira natural, organizada e adequada ao seu desenvolvimento, principalmente à criança surda, que estará ingressando no aprendizado da escrita de outra língua.

Vigotski et al. (1930/ 1988), afirmam apoiados em suas pesquisas, que a fase pictográfica do desenvolvimento da escrita baseia-se na rica experiência dos desenhos infantis. Inicialmente o desenho é brincadeira, um processo autocontido de representação; em seguida, o ato completo pode ser usado como estratagema: o desenho transforma-se, passando de simples representação para um meio, e o intelecto adquire um instrumento novo e poderoso na forma da primeira escrita diferenciada.

Os experimentos desenvolvidos por Luria (1930/ 1988), pesquisador responsável por recriar experimentalmente o processo de simbolização na escrita de modo a poder estudá-lo de forma sistemática, mostram que crianças colocadas diante da tarefa de representar graficamente frases mais ou menos complexas, revelam a passagem de desenhos a formas mais próximas da escrita. As crianças vão da escrita pictográfica para uma escrita ideográfica, criando marcas simbólicas. Ou seja, seus estudos revelaram que a criança antes de adquirir a escrita, passa por um longo processo que vai do uso de rabiscos não figurativos 
(garatujas), utiliza-se posteriormente de imagens e figuras diferenciadas, para então chegar aos signos.

Em suas reflexões, Luria também constatou que, na fase inicial, a relação da criança com a escrita se dá pela mera imitação do adulto, não havendo ainda compreensão de seu significado. Somente quando o símbolo passa a ser interpretável efuncional nos seus registros, é que ocorre o aprendizado das letras e o domínio da escrita.

Mas, o ato de escrever não significa necessariamente que o processo de escrita tenha sido compreendido. A habilidade de escrever precede sua compreensão. Torna-se necessário à criança tentar, criar, construir e reconstruir hipóteses para se apropriar e usar significativamente a escrita como sistema simbólico.

Já na atividade discursiva, a fala, é a porta de acesso à ordem simbólica, e a criança já nasce inserida nela como objeto do discurso do outro. Desde o início ela é sujeito de ações significantes para o outro, o que a insere irremediavelmente no circuito do simbólico (PINO, 2005).

De acordo com Lacerda (2004) o desenvolvimento de narrar em crianças éal go corriqueiro, facilmenteobservável, especialmente quando a criança brinca, desenha ou está diante de outros interlocutores, sejam eles adultos ou crianças. Porém, a emergência da narrativa pode ser mais dificilmente observada quando o desenvolvimento de linguagem como um todo está prejudicado.

A linguagem é social e acontece pela interação e pelas trocas entre as pessoas, que vão se modificando ao longo do desenvolvimento, pois implicam em possibilidades e ajustes entre os interlocutores.

Toda criança passa por processos de imitação, através dos quais vai conhecendo, descobrindo e aprendendo coisas sobre o mundo. Em um primeiro momento, ela imita o outro, tomando-o como um espelho, e é pela ação do outro (imitada) que a criança vai se apropriando dos conhecimentos de mundo. Ela começa a descobrir aspectos novos e passa a explorar o mundo ao seu redor, agindo de forma mais autônoma. Ela vai interiorizando a linguagem que colabora também para organizar sua atividade mental, construindo seu pensamento, favorecendo que ela passe a se expressar sozinha, mais independentemente.

Nesse contexto, a criança descobre a palavra e vai percebendo a linguagem como um processo dinâmico, pleno demúltiplos sentidos esignificados. Assim, o interlocutor adulto colabora para que a linguagem da criança flua e lhe permita as atitudes discursivas que a levem a aprender a identificar aspectos importantes da língua que ela irá se apropriar.

A narrativa permite a organização no tempo e no espaço, o compartilhar dos relatos de fatos da vida cotidiana, os segredos, os desejos, as estórias ouvidas, vividas e imaginadas. A estória infantil, retratada em livros e 
filmes, favorece de maneira significativa a construção de experiências de narrar, sendo estas atividades (ler livro, assistir filme, contar e recontar a estória) freqüentes nas relações adulto-crianças ouvintes.

Os atos de leitura e de reflexão sobre o que foi lido e visto, a possibilidade de análise, exploração e interpretação de livros e de filmes, a consideração dos aspectos relativos à interlocução (troca de papéis), podem contribuir para o enriquecimento lingüístico esócio-histórico-cultural das crianças e para sua constituição como futuros leitores-escritores.

Contudo, se a significação, o sentido e a interpretação são fundamentais para o desenvolvimento e a aquisição da linguagem, a criança surda, filha de pais ouvintes, não tem essa oportunidade, freqüentemente, porque todas as experiências circundantes são ditas ou realizadas em uma língua não acessível. Então, aquilo que ela percebe, tem intenção de perguntar ou o que lhe é dito, nem sempre é significado.

O não acesso à língua do grupo majoritário impede que o desenvolvimento simbólico e a construção da significação se dêem de forma harmoniosa, conseqüentemente, esta criança poderá apresentar atraso de linguagem e o acesso à escrita ficará ainda mais complicado.

Nesse sentido, o acesso precoce à língua de sinais é fundamental para que a criança surda se desenvolva lingüisticamente e tenha possibilidades para comunicar seus desejos, necessidades e opiniões. A língua de sinais permite à criança surda significar o mundo ea si própria, já que essa tem papel constitutivo na subjetividade. Portanto, quanto mais tardia a aquisição, mais comprometido pode ficar o desenvolvimento do sujeito.

Entretanto, a partir da perspectiva Histórico-Cultural, são escassas as referências sobre o circuito e funcionamento destas esferas simbólicas (gesto, desenho, narrativa, escrita, sinais) sobre suas relações, inter-relações e as possibilidades desua interferência no desenvolvimento da linguagem edo sujeito surdo em seus aspectos constitutivos. E, ao se pensar também na surdez, não se pode perder de vista que, o desenvolvimento da linguagem só será possibilitado, se o profissional ouvinte e criança surda, estiverem trabal hando na mesma língua e ambos imersos no mesmo mundo simbólico.

Desta maneira, este estudo ancora-se na abordagem bilíngüe para explorar e abordar as esferas simbólicas da linguagem - gesto, desenho, narrativa e escrita - concomitante à língua de sinais no desenvolvimento de linguagem da criança surda e na construção de novos conhecimentos. 


\section{MÉTOdo}

Para estudar a linguagem eseus processos dedesenvolvimento, alguns pesquisadores têm buscado realizar pesquisas que levem em conta o sujeito, seu contexto e sua história desenvolvendo metodologias de pesquisa próximas às abordagens qualitativas, valorizando mais os processos em sua ocorrência do que os produtos finais al cançados (FREITAS, 2001; LODI, 2004; ARAÚJO, 2008). Esta forma de abordagem, articulada a análise microgenética (WERTSCH; HICKMANN, 1987) como abordagem metodológica inscrita em uma interpretação histórico-cultural e semiótica dos processos humanos (VIGOTSKI, 1926/ 1996), configuram-se como as mais adequadas aos propósitos deste estudo.

De acordo com Góes (2000, p. 9) salienta-se o caráter promissor de tais tendências para a investigação da constituição do sujeito, pois elas permitem adensar o estudo dos processos intersubjetivos e expandem as possibilidades de "vincular minúcias de episódios específicos a condições macrossociais, relativas às práticas sociais."

Os sujeitos da pesquisa ${ }^{6}$ foram duas crianças surdas (aqui denominadas de $\mathrm{J} \mathrm{e} \mathrm{LC}^{7}$ ambas do sexo masculino; faixa etária de 9 e 10 anos respectivamente, com diagnóstico audiológico de surdez profunda bilateral e queixa de atraso do desenvolvimento de linguagem

Freqüentavam a mesma sala de 2a série do Ensino Fundamental em uma escola pública integrante de um programa deinclusão de educação bilíngüe ${ }^{8}$. Usuários tardios da Língua Brasileira de Sinais (Libras) e filhos de pais ouvintes, estavam se apropriando desta língua ao mesmo tempo em que eram solicitados a aprender o Português, na modalidade escrita. Tratava-se de uma língua da qual não eram usuários. Práticas de letramento comuns ao ambiente familiar eram pouco acessíveis a eles, já que suas famílias tinham domínio precário da língua de sinais. Por sua constituição como sujeitos surdos e usuários da Libras, a escrita era algo novo e distante.

\footnotetext{
${ }^{6} \mathrm{O}$ protocolo desta pesquisa bem como o Termo de Consentimento Livre e Esclarecido apresentado ao Comitê de Ética em Pesquisa em 24/ 11/ 2003 foi homologado na XII Reunião Ordinária do CEP/ FCM em 16/ 12/ 2003 e aprovado sob o № 565/ 2003.

7 Os responsáveis pelos sujeitos pesquisados autorizaram o uso de seus nomes.

${ }^{8}$ Existe no município onde foi realizada a pesquisa, um programa de inclusão escolar bilíngüe para crianças surdas, que busca respeitar suas condições lingüísticas e necessidades educacionais. Assim, os sujeitos pesquisados freqüentavam uma escola referência no atendimento à surdez para o Ensino Fundamental. A escola contava com instrutor surdo para o ensino de Libras (oferecido aos funcionários da escola) e para a condução de oficinas de Libras (oferecidas aos alunos surdos para desenvolvimento de linguagem). Contava também com intérprete de língua de sinais em sala de aula para tradução e interpretação dos conteúdos ministrados.
} 
O trabalho foi desenvolvido no Setor deSurdez de uma Clínica-Escola de Fonoaudiologia9, no interior de São Paulo, ao longo de um ano, compreendendo tanto o atendimento clínico-terapêutico quanto a participação em Oficina de Libras $^{10}$, em sessões semanais de sessenta minutos cada.

No segundo semestre do atendimento, as crianças escolheram trabalhar com atividades do R ei Leão $0^{11}$. Dentro dessa temática, foram então explorados filme de vídeo, livros deestória, miniaturas dos personagens principais da estória (Simba, N ala, Timão e Pumba).

O atendimento terapêutico da dupla visava o desenvolvimento de linguagem (ampliação da Libras e da escrita, focando o texto escrito, forma de representação do Português, rejeitada inicialmente pelas crianças dadas as suas dificuldades de aprendizagem e compreensão) e a construção de conhecimentos, a partir do trabalho com as esferas simbólicas - gesto, narrativa, desenho, escrita e língua de sinais. Foi conduzido pela fonoaudióloga pesquisadora (aqui denominada de terapeuta).

A pós a terapia de linguagem, as duas crianças participavam da oficina de Libras conduzida por um instrutor surdo adulto e fluente em Libras (aqui denominada de instrutora surda) cujo objetivo era o de ampliar os conhecimentos dos interlocutores nessa língua, consolidando-a. Eventualmentea instrutora surda participava das sessões de Fonoaudiologia para favorecer a dialogia em Libras, já que a terapeuta tinha um domínio restrito desta língua.

O foco das análises privilegiou a emergência dos processos em mudança na dinâmica das interações entre os sujeitos que participaram da pesquisa, considerando o aspecto particular e global na sua ocorrência e constituição. A construção dos dados envolveu exame dos conjuntos de vídeos das crianças focais e seleção de episódios de interesse a presente discussão, explorando os aspectos da inter-relação das atividades simbólicas (gesto, narrativa, desenho, escrita, língua de sinais) e os modos como esta inter-relação incidiu sobre tentativas de produção e apropriação da linguagem escrita pelas crianças surdas.

\footnotetext{
${ }^{9}$ Este estudo insere-se no Projeto de Pesquisa "O papel do instrutor surdo no ensino de língua de sinais para a comunidade surda e familiares da clínica-escola de fonoaudiologia da UNIMEP" - CEP/ UNIMEP: 15/ 02, CONEP: 196/ 96 - desenvolvido pelas pesquisadoras Profa. Dra. Cristina Broglia Feitosa de Lacerda, Profa. Dra. Sueli A parecida Caporali e Profa. Dra. Ana Cláudia Balieiro Lodi.

10 Oficinas de Libras são um espaço destinado aos sujeitos surdos com o objetivo de propiciar o desenvolvimento lingüístico dos mesmos, focalizando aquisição e desenvolvimento de Libras, fluência em Libras, construção de conhecimentos e reflexões sobre aspectos culturais e identitários relativos à surdez.

${ }^{11}$ Com inspirações vindas de "Hamlet" (1601) de William Shakespeare, "O Rei Leão" (1992) de Walt Disney, conta a estória de Simba, um filhote de leão nascido nas selvas africanas, cujo tio Scar, se apodera do trono após matar seu pai, o rei Mufasa. Simba é injustamente acusado pela morte do pai e se vê obrigado a exilar-se das terras do reino. Recordista de bilheteria, este clássico é ainda sucesso nos dias de hoje, e dentre os seus vários produtos comercializados, destacam-se neste artigo, filme (fita de vídeo), livros e miniaturas dos principais personagens da estória.
} 
De acordo com Góes (2000) a possibilidade de trabalhar com recortes de eventos orientados para minúcias indiciais e em um tempo que tende a ser restrito, permite focal izar o movimento durante processos e relacionar condições passadas e presentes, tentando explorar aquilo que, no presente, está impregnado de projeção futura. Buscando-se também referir eventos singulares aos diversos planos da cultura, serão apresentados os episódios a seguir em ordenamento cronológico do mais antigo para o mais recente.

\section{Resultados}

\subsection{EpIsódio 1: NarRativa}

As crianças tiveram a oportunidade de ver o filme R ei Leão na oficina de Libras, com a instrutora surda, que procurava chamar a atenção de J e LC para as imagens das cenas, explicando-Ihes pequenos episódios através da língua de sinais. Os nomes dos personagens eram dados em datilologia.

Eles davam retorno, produzindo sinais: LC com maior domínio e J com menor. Às vezes, faziam comentários adequados, dando a idéia de que estavam entendendo, e às vezes, não. Embora a sessão estivesse permeada por Libras, não havia a configuração de um diálogo, eram fragmentos de narrativa: os comentários da instrutora surda e dos participantes nem sempre seguiam uma mesma direção, ou mantinham o mesmo foco, havia muitas dúvidas, e os sinais das crianças surdas, geralmente, eram imprecisos. Ressalta-se que era um filme longo, com um enredo denso em certos aspectos, e nem sempre as cenas eram claras em seu sentido, apenas por suas imagens. Em muitos momentos, o que era dito nos diálogos, entre os personagens, não podia ser percebido apenas pela cena apresentada no vídeo.

Com a estória já discutida e conhecida por meio do filme, as crianças foram convidadas no atendimento terapêutico, a folhear e explorar livros desta mesma estória, que foi narrada novamente em Libras pela instrutora surda. Em um primeiro momento, J e LC dramatizaram algumas cenas, usando gestos e as principais miniaturas de personagens (Simba, $\mathrm{N}$ ala, Timão e Pumba).

A Libras aparecia de uma maneira ainda muito inicial: os comentários de LC eram em Libras, mas como descrição, ou seja, ele via a imagem no vídeo e a descrevia/ repetia em seus gestos e movimentos. J ainda não usava os sinais autonomamente (sempre buscava a confirmação da instrutora surda para seus sinais). Embora as crianças usassem os sinais que sabiam adequadamente, ainda não havia um domínio de língua que permitisse narrar, ou perguntar, ou mesmo descrever com qualidade aquilo que apreendiam da estória. O que se observava eram comentários breves, característicos de um domínio restrito de língua. 


\section{2 - Episódio 2: Desenho}

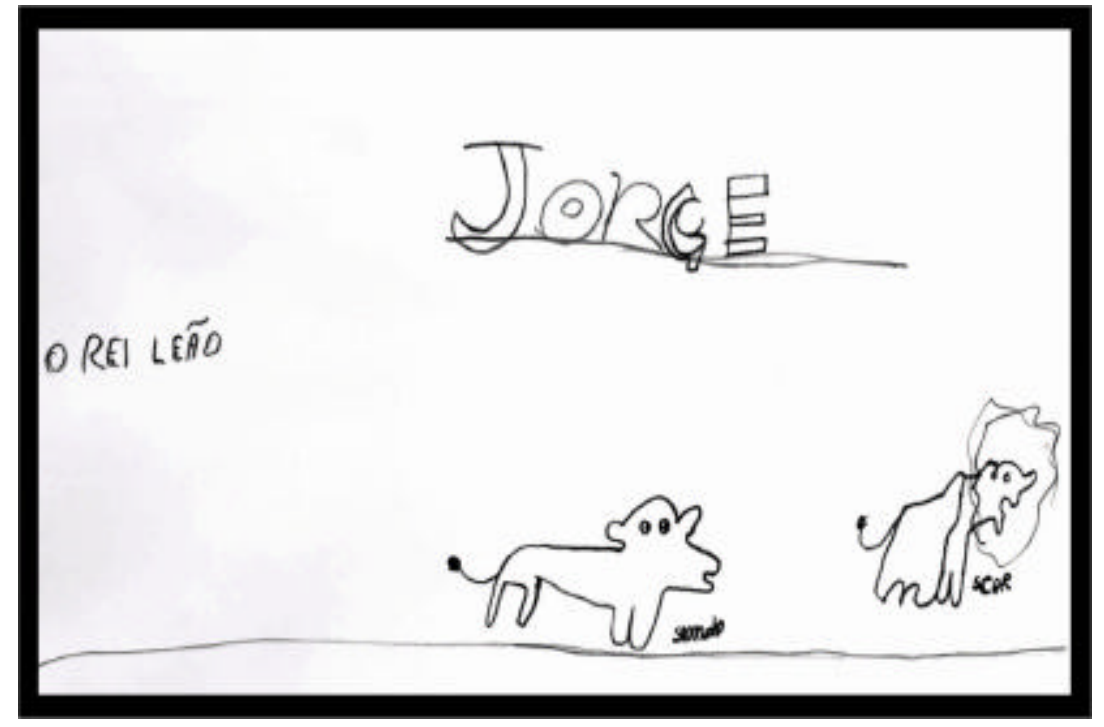

Figura 1 - Desenho de J

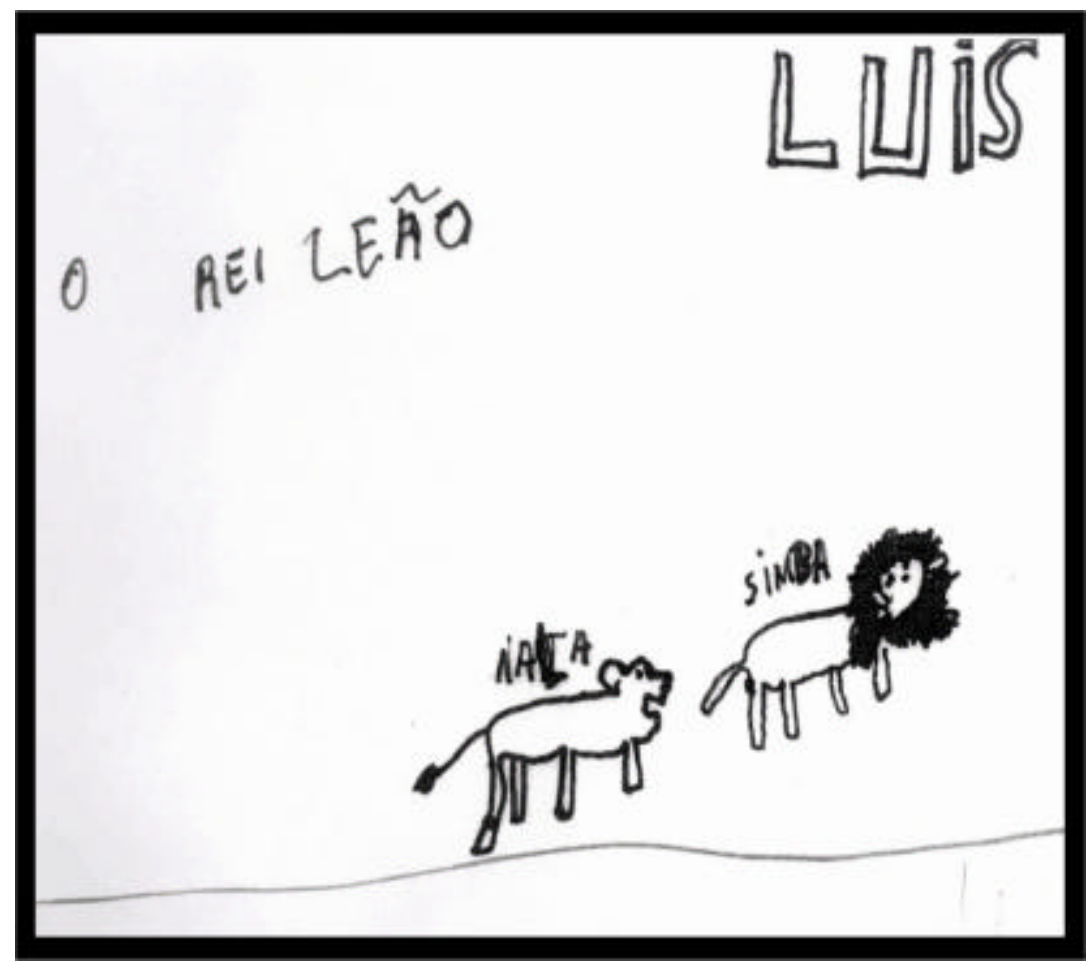

Figura 2 - Desenho de LC 
A pós assistirem o filme e folhearem livros, foi no desenho que J e LC mais se expressaram, denotando um momento importante da elaboração e compreensão simbólica sobre as atividades trabal hadas até então.

Com o livro aberto na estória do Rei Leão, a ilustração servia como parâmetro para a composição das figurações das crianças.

Ora as crianças desenhavam sozinhas, ora uma interferia no desenho da outra, dando pal pites. Em certo momento, discordaram e discutiram: LC olhou para o desenho de J (Figura 1) e desenhou uma juba (Figura 2) da mesma cor da juba do leão de J.

J tentava com sinais, explicar que a juba de Simba (leão desenhado por LC) era clara. Somente a juba de Scar (o leão mau representado em seu desenho) era preta. Como LC não Ihe dava atenção, levantou-se da cadeira em que estava assentado e dramatizou a cena que havia desenhado, na qual Scar acusava Simba de matar o pai: como sua representação pelo desenho e seus argumentos não conveceram o amigo, ele recorreu à dramatização como forma de se fazer entender e argumentar. Ainda assim, não conseguiu convencer o amigo, que desenhou com mais força ainda, a juba preta no seu leão, representando a cena na qual $\mathrm{N}$ ala e Simba conversavam sobre o seu retorno às terras do reino.

A terapeuta interveio e pediu que cada criança escrevesse o nome do leão desenhado como forma de marcar melhor qual personagem estava sendo representado por cada um. J se recusou em princípio, ficou reticente, argumentou contra, deixando claro que não queria escrever. Mas, a terapeuta insistiu, deu pistas objetivas mostrando o nome do personagem no livro, e aos poucos ele foi se sentindo mais seguro, até que aceitou a proposta e escreveu (Figura 1). Com LC não foi diferente. Diante da proposta de escrever, esquivou-se efez o sinal em Libras de leão, mostrando seu conhecimento e reafirmando a não necessidade de escrever. A terapeuta insistiu na escrita do nome do personagem, e dessa vez, LC tentou por meio da datilologia ${ }^{12}$ mostrar que conhecia o nome de Simba. Fez algumas letras (S-I-B), mas não conseguiu indicar todas as letras da palavra pretendida. A terapeuta também Ihe mostrou o nome escrito no livro e, após toda essa negociação, LC o copiou letra por letra (Figura 2).

O que J, LC e terapeuta conheciam da língua de sinais, mostrou-se suficiente para negociar os sentidos pretendidos na situação, que favoreceram que al guma escrita fosse emergindo, naquele momento fortemente ancorada nos desenhos produzidos.

${ }^{12}$ Alfabeto digital 
Neste episódio a escrita foi usada para nomeação, como etiqueta, de maneira apropriada: nome próprio dos participantes, nome do filme e nome dos personagens. Esta escrita revelou-se significativa para LC e J, pois, garantia um sentido mais preciso àquilo que cada um deles pretendia representar com seu desenho (nome da figura desenhada, da estória que foi contada e de quem desenhou). O desenho, meio de expressão inicialmente mais fácil para eles, favoreceu a emergência da escrita a partir dos diálogos estabelecidos em Libras.

O quese observa são esferas deatividade simbólica seinterpenetrando efavorecendo o desenvolvimento simbólico como um todo, abrangendo inclusive a escrita - atividade mais complexa - e que não pode ser alcançada pelas crianças surdas a partir de sua oralidade, como é freqüente em crianças ouvintes.

\subsection{EpIsódio 3: EsCRITA}

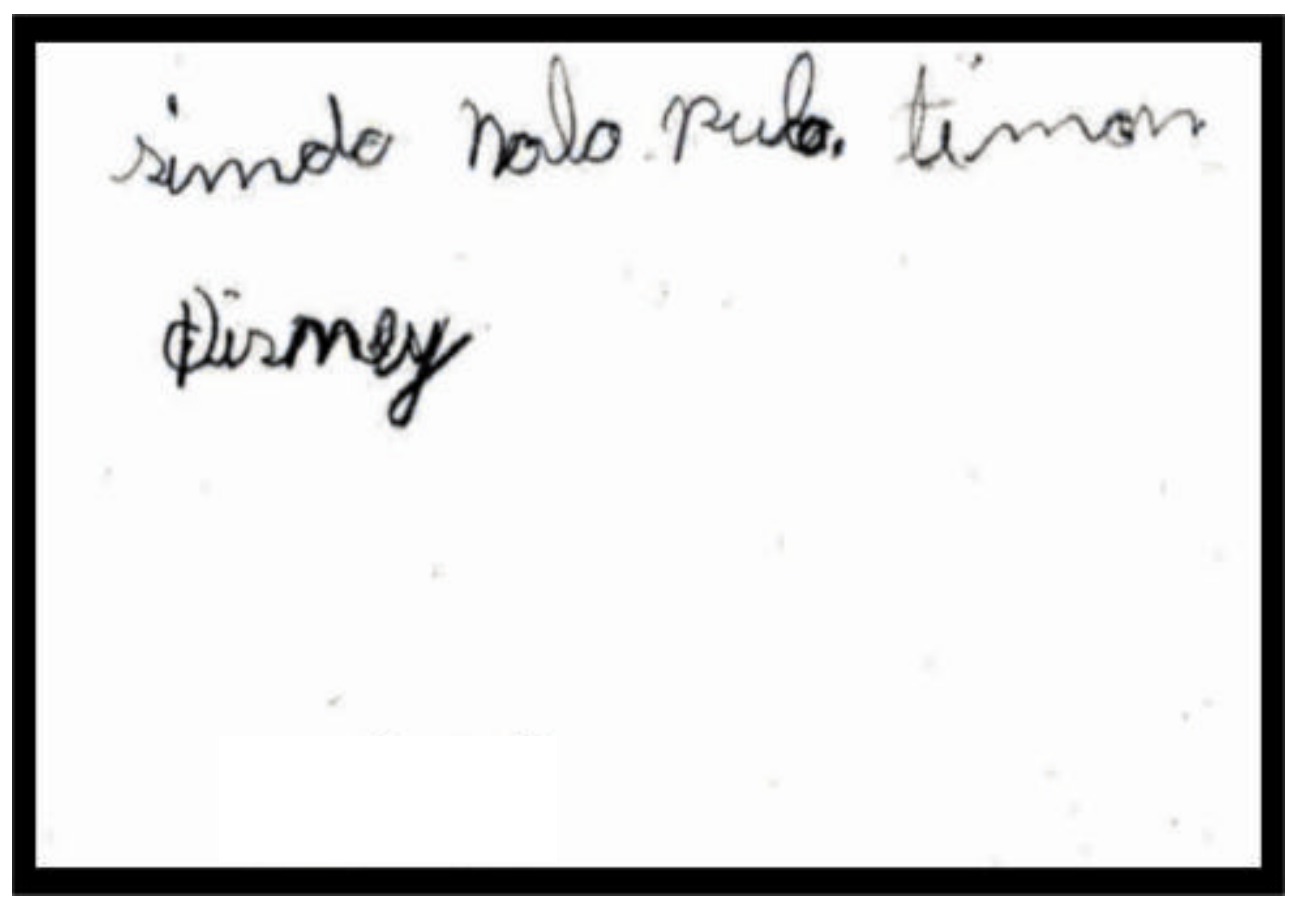

Figura 3 - Escrita de J 


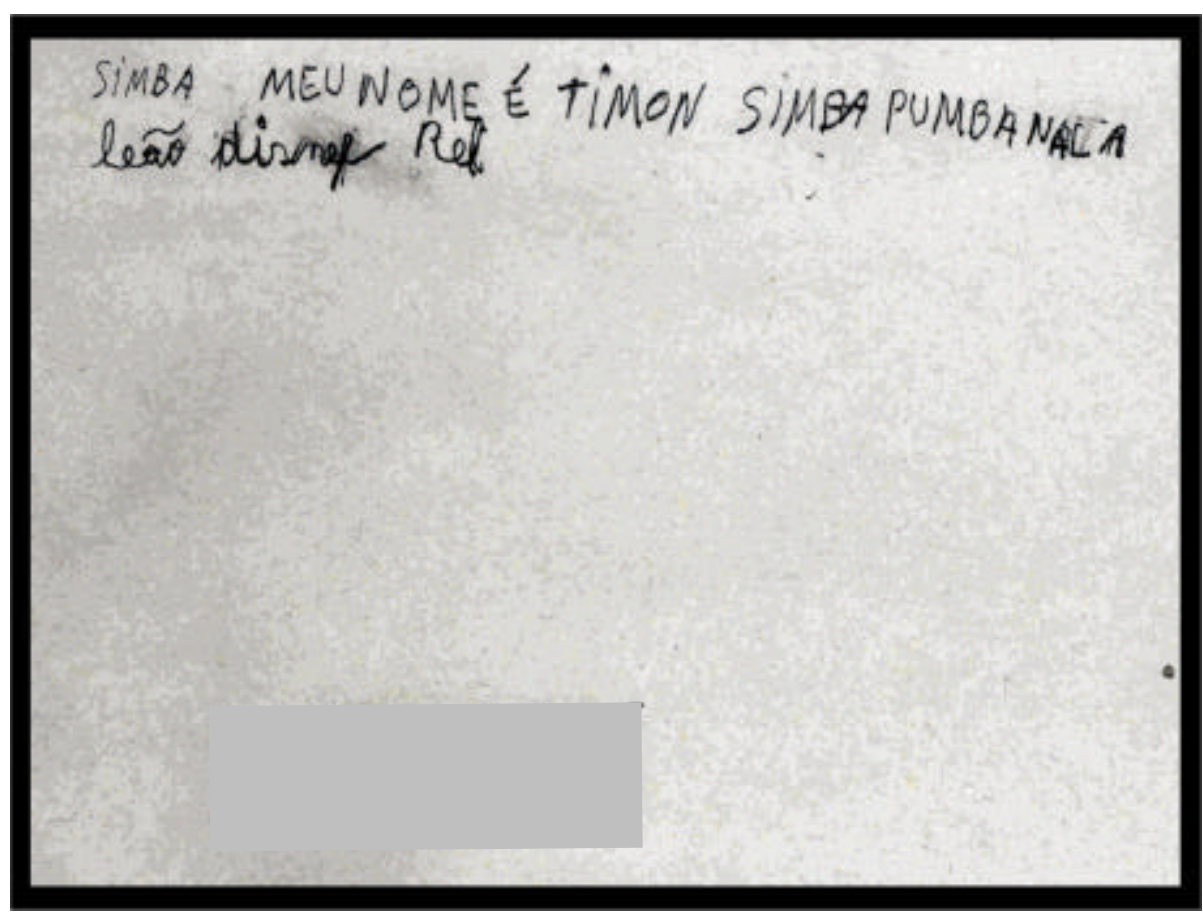

Figura 4 - Escrita de LC

Em uma sessão de atendimento clínico-terapêutico foi oferecido a J e LC um livro contendo várias estórias de Walt Disney. LC assumiu inicialmente a tarefa de ler o livro contando as estórias a partir das ilustrações, fazendo breves descrições das figuras em Libras. Era um início de narrativa autônoma, guiada pelas imagens presentes no livro. É importante considerar que LC não conhecia muitas daquelas estórias, e então não tinha conhecimentos prévios suficientes para narrá-las, a não ser descrevendo as ilustrações. Descrevia-as como se fossem parte de um álbum de figuras, sem continuidade ou conexão entre elas. J acompanhava as atitudes de LC apenas olhando. Diante da postura de leitor, LC passava o dedo rapidamente pelas linhas do livro, apontando para as imagens, fazendo sinais pertinentes às ilustrações. Diante do mesmo material (estórias desconhecidas) J não se mostrava interessado em sinalizar, mas apenas folheava o livro, observando as ilustrações.

Quando folheando o livro chegaram à estória do Rei Leão, os dois estabeleceram uma parceria diferente, e houve uma tentativa de recuperar o sentido mais amplo da estória, por esta já ter sido vista em filme, sinalizada em Libras, dramatizada e desenhada na terapia. Na maior parte do tempo,J fol heava o livro e LC tentava fazer sinais de acordo com a ilustração, chamando a atenção para alguma página ou retornando a ela, buscando estabelecer uma seqüência 
entre aquilo que ele via e o que ele contava. Neste momento, observa-se a emergência de um discurso narrativo melhor consolidado, apoiado nas imagens e em seus conhecimentos anteriores, com uma seqüência de argumentos narrados em Libras.

Algumas vezes, J também descrevia os personagens e situações, iniciando-se em uma narrativa mais tímida se comparada àquela apresentada por LC, contudo, nessas trocas, uma criança complementava a outra, ampliando as possibilidades de cada um. A instrutora surda chamou a atenção de J para a leitura de nomes: Simba, Nala e de outros personagens. Interessado por essa atividade, J passava o dedo pelas linhas do livro e quando achava alguma palavra que conhecia, atribuía-Ihe o sinal pertinente e mostrava a ilustração correspondente. O queJ conhecia da estória pela imagem visual, mais as ilustrações do livro, é que permitiram a fixação de sua atenção ao texto escrito e no reconhecimento de palavras. Observa-se assim, os primórdios desua atitude como leitor, confiante de suas possibilidades.

O texto escrito começou a aparecer como foco de interesse para as crianças, e a terapeuta procurava, sempre que possível, associar a ilustração/ figura ao texto escrito do livro, buscando constituir significação também nele, sugerindo a leitura e escrita de pal avras. Sem contrariedadee com base nos signos já constituídos (pela imagem, pela Libras, pelo desenho) as crianças buscaram sentidos no texto e mostraram-se competentes no reconhecimento de palavras e na escrita de nomes de personagens que mais se destacavam visualmente e se repetiam ao longo do texto (Figura 3 de J e Figura 4 de LC).

O nome Disney chamou a atenção de J pel o fato de estar presente em todos os livros do Rei Leão (havia um livro para cada criança e para cada adulto), levando-o a especular, pensar e inferir que era mais um personagem da estória. A terapeuta explicou que esse era o nome do autor do livro. Imediatamente LC, seguido de J, escreveram seus respectivos nomes nas folhas, identificando o que tinham escrito como uma estória, em que se marca a autoria.

Este episódio revela uma escrita que já começa no início da página, com letra cursiva e/ ou de forma, da esquerda para direita até o término da linha, indicando conhecimentos e produções muito valorizadas socialmente.

\section{Discussão}

A Clínica Fonoaudiológica é majoritariamente oralista. Recebe a criança com diagnóstico precoce desurdez ea grandemaioria deseus profissionais (90\%) indica a protetização e o trabalho com a oralização (LACERDA et al., 2000). Se a criança não vai bem nesse modelo de atendimento, aí sim, surge, já tardiamente, a língua de sinais. Nesse contexto, a maioria das crianças surdas chega à escola sem oral idade esem Libras, prejudicando edificultando a aquisição da leitura e escrita do Português. 
Tentando minimizar e reverter este quadro, alguns fonoaudiólogos têm investido na abordagem bilíngüe, priorizando a aquisição precoce da língua de sinais, para posterior trabalho com a escrita ou oralidade (quando possível) da língua nacional. Nesta perspectiva, foi desenvolvido este trabal ho em uma Clínica-Escola de Fonoaudiologia no interior de São Paulo.

$\mathrm{Na}$ Perspectiva Histórico-Cultural, modelo teórico que embasa este estudo, os elementos mediadores na relação entre o homem e o mundo instrumentos, signos e todos os elementos do ambiente carregados de significado cultural - são fornecidos pelas relações entre os homens. Os sistemas simbólicos e, particularmente a linguagem, exercem papel fundamental na comunicação entre os indivíduos e no estabelecimento de significados compartilhados que permitem interpretações dos objetos, eventos e situações do mundo real (OLIVEIRA, 1998).

De acordo com a teoria Histórico-Cultural a história do desenvolvimento da linguagem escrita tem suas raízes na interação social. Como representação, tem início com o aparecimento do gesto como signo visual, e posteriormente com o desenho, quando a criança percebe a possibilidade do deslocamento de desenhar objetos para desenhar a fala, até que a ação e o grafismo passam a se subordinar aos processos de significação (VIGOTSKI et al., 1930/ 1988; LURIA, 1930/ 1988). Assim, o desenvolvimento do grafismo infantil, não pode ser visto como um processo mecânico, nem como uma construção individual da criança. Os conhecimentos e habilidades são construídos a partir de relações interpessoais (plano interpsíquico) e depois são internalizados e transformados ao nível intrapessoal (plano intrapsíquico).

Estes autores concluem que o gesto, a narrativa, o desenho e a escrita devem ser vistos como momentos diferentes de um processo essencialmente unificado - mesmo considerando as descontinuidades e os saltos de um tipo de atividade para outra - de desenvolvimento da linguagem escrita. A firmam ainda, que a leitura e a escrita devem ser algo de que a criança precise, uma tarefa necessária e relevante para a vida, como uma forma nova e complexa de linguagem que ocorre em um momento natural no seu desenvolvimento.

Para então se chegar ao texto escrito do Português, língua cuja modalidade precisava ser significada simbolicamente para poder ser compreendida, o contexto e cotidiano terapêutico foi marcado pelo uso intensificado de atividades dentro da temática da estória Rei Leão, significadas, narradas e interpretadas pela Libras.

Os estímulos para o desenvolvimento de linguagem estavam fortemente apoiados em imagens (configuração visual): filme, livro, miniaturas de personagens, e a partir dessas imagens relacionadas às atividades (assistir filme, explorar livro, narrar, desenhar) emergia a língua de sinais, novos conhecimentos e possibilidades de abordar a leitura e a escrita. 
Os episódios mostraram o fluxo da atividade si mbólica utilizado para representar um todo de significação. No primeiro episódio, a instrutora surda, diante do filme Rei Leão, explicava o que estava acontecendo, enfatizando principalmente as cenas possíveis de interpretação pela imagem. Pelo nível de domínio de Libras das crianças, configurou-se uma sessão, na qual as crianças assistiam ao filme e faziam comentários breves e fragmentados sobre o que estavam entendendo. As crianças não tinham ainda domínio suficiente de Libras para dizer tudo o que precisavam ou queriam.

A exploração do livro de estória já permitiu que as crianças, naquele momento, a representassem por meio de gestos e dramatização. Tais atividades mostraram-se prazerosas para as crianças, e apoiadas principalmente no desenho, elas puderam compreender vários elementos da estória, além de se desvencilhar da impressão inicial e negativa sobre a leitura e escrita, em um momento fundamental de seu desenvolvimento.

Pela limitação nos usos de linguagem, o desenho foi uma ferramenta terapêutica potencialmente capaz de contribuir para a emergência de processos favoráveis ao desenvolvimento da linguagem de J e LC, tornando-se possível atentar para os modos de expressão e representação destas crianças, acerca de suas experiências com as atividades trabalhadas. Elas desenharam o que haviam visto no filme e no livro, figurando importantes cenas do Rei Leão. Arriscaramse na escrita, copiando do livro de estória, inicialmente, letra por letra, tanto o nome do filme quanto o de personagens. Também colocaram seus nomes em letras grandes e elaboradas.

A partir daí, já no tercei ro episódio, as crianças sentiram que podiam narrar. É fundamental para o desenvolvimento da linguagem e da escrita a criança assumir/ ocupar o lugar de narrador: elas tinham o que dizer, e nesse momento mais acessível, elas narrraram apoiadas na ilustração (imagem visual), ampliando a Libras. E, quando J e LC engajaram-se na atividade de produção de conhecimento compartilhado, foi possível vislumbrar situações propulsoras de novos conhecimentos. O foco nas atividades simbólicas para a constituição da linguagem passou a ser estendido também para o texto escrito.

Considerando que as crianças sempre apresentaram grande resistência à leitura e escrita de textos, ressalta-se então, a importância do trabalho fonoaudiológico apoiado em atividades interessantes e significativas para elas, possibilitando que J e LC, a partir de atividades simbólicas melhor consolidadas (desenho, dramatização, narração) internalizassem aspectos iniciais da escrita, transformando suas experiências pessoais. De acordo com Vigotski (1935/ 1998) no percurso deste desenvolvimento, a criança reconstrói internamente as operações externas, e os vários sistemas sígnicos cooperam e operam como sistemas fundamentais para que ela possa internalizar ações vividas socialmente. É desta forma que são constituídas as funções psicológicas superiores. 
Ao analisar estes episódios foi possível observar a relação e interrelação lingüístico-cognitiva entre gesto, desenho, narrativa, sinais e escrita. Explorou-se em cada episódio, quando havia maior domínio de uma esfera sobre a outra, quando elas se compunham, o momento em que uma favorecia e constituía a(s) outra(s). Ora as crianças tentavam, ora se esquivavam, ora se aproximavam, ora seafastavam destas esferas, mas mesmo com descontinuidades, sempre havia movimento, favorecendo a circulação de linguagem.

Ou seja, o filme colaborou para significar a estória, que foi narrada em Libras pela instrutora surda. Pelas imagens do filme e do livro as crianças, inicialmente, vivenciaram a estória pelos gestos, pela dramatização, e a representaram no desenho e na escrita.

O apoio na imagem gerou conversa, que gerou desenho, que gerou comentários, discordâncias, dramatização, datilologia e tentativas de escrita, que por sua vez, foram comparadas à ilustração, às miniaturas de personagens.

Pelo fluxo destas atividades, ampliaram-se os sinais, que permitiram a narrativa de cenas, o reconhecimento de nomes no texto e a aproximação da escrita, de maneira prazerosa.

A s atividades simbólicas abriram espaço para a consol idação de signos (da significação), que por sua vez, favoreceram a emergência da Libras (maior consolidação) e os primórdios da escrita. Pela mediação simbólica/ semiótica e interação social, pensamento, linguagem e conhecimento foram constituídos.

\section{CONCLUSÕES}

Aos profissionais da área da saúde e da educação, interessa significativamente o desenvolvimento da linguagem e da criança surda, cujo atraso a impede de constituir-se subjetivamente e de atuar socialmente, principalmente na fase de aquisição da leitura e escrita.

As atividades simbólicas se consolidam por meio das impressões que a criança constrói sobre o seu universo cultural ehistórico. Entender este processo na surdez compreende o trabalho com a linguagem, resultante da imersão no mundo simbólico comum à terapeuta/ professor/ pedagogo e criança.

Neste sentido, as observações feitas, fortalecem o argumento da importância da língua de sinais e da atividade do desenho, como recurso sígnico, para que as possibilidades do desenvolvimento lingüístico e cognitivo sejam alcançadas e contemplem os aspectos psicossociais destas crianças que buscam ser bilíngües. 


\section{REFERÊNCIAS}

ARAÚJO, C.C.M. Linguagem e desenho infantil: aspectos do desenvolvimento simbólico da criança surda e implicações terapêuticas. 2008. 137f. Tese(Doutorado em Saúde da Criança edo A dolescente) - Centro del nvestigação em Pediatria, UniversidadeEstadual deCampinas, Campinas.

FERNANDES, S. Letramentos na educação bilíngüe para surdos. In: BERBERIAN, A.P.; AN GELIS, C.M.; MASSI, G. (Org.). Letramento: referenciais em saúde eeducação. 1. ed. São Paulo: Plexus, 2006. p. 117-44.

FERREIRA, S. I maginação elinguagem no desenho da criança. 1. ed. Campinas: Papirus, 1998.

FREITAS, A.P. Z ona de D esenvolvimento Proximal: a problematização do conceito através de um estudo de caso. 2001. 133f. Tese (Doutorado em Educação) - Faculdade de Educação, UniversidadeEstadual de Campinas, Campinas.

GÓES, M.C.R. A abordagem microgenética na matriz histórico-cultural: uma perspectiva para o estudo da constituição da subjetividade. Cadernos Cedes. Campinas, v. 20, n. 50, p. 9 25, 2000.

GUARINELLO, A.C.; LACERDA, C.B.F. O grupo de familiares de surdos como espaço de reflexão e de possibilidades de mudança. In: SANTANA, A.P. et al. A bordagens grupais em Fonoaudiol ogia: contextos e aplicações. 1. ed. São Paulo: Plexus, 2007. p. 105-120.

LACERDA, C.B.F. O desenvolvimento do narrar em crianças surdas: focalizando as primeiras produções em sinais. R evista da Sociedade Brasileira de F on oaudiol ogia, São Paulo, v. 9, n. 2, p. 65-72, 2004.

. NA KAMURA, H.; LIMA, M.C. (Org.). Surdez e abordagem bilíngüe. 1. ed. São Paulo: Plexus, 2000.

LODI, A.C.B. Educação bilíngüepara surdos. In: LACERDA, C.B.F.; NAKAMURA, H.; LIMA, M.C. (Org.). Surdez eabordagem bilíngüe. 1. ed. São Paulo: Plexus, 2000. p. 64-83.

. A leitura como espaço discursivo de construção de sentidos: oficinas com surdos. 2004. 165f. Tese (Doutorado em Lingüística A plicada e Estudos da Linguagem) - Pontifícia UniversidadeCatólica deSão Paulo, São Paulo.

LURIA, A .R. O desenvolvimento da escrita na criança. In: VYGOTSKY, L.S.; LURIA, A. R.; LEONTIEV, A.N. Linguagem, desenvolvimento eaprendizagem. 3. ed. São Paulo: Ícone/ Edusp, 1988 [original de 1930].

MASINI, L. Considerações sobre o processo terapêutico fonoaudiológico no trabal ho coma escrita. In: DAUDEN , A.T.B.C.; A N GELIS, C.C.M. Linguagem eescrita: tendências ereflexões sobre o trabalho fonoaudiológico. 1. ed. São Paulo: Pancast, 2004. p. 65-86.

OLIVEIRA, M.K.Vygotsky - A prendizado e D esenvolvimento: um processo sócio-histórico. 1. ed. São Paulo: Scipione, 1998.

PADILHA , A.M.L. Práticas educativas: perspectivas queseabrem para a Educação Especial . Educação e Sociedade, Campinas, v. 2, n. 71, p. 197-220, 2000.

PIN O, A. A s marcas do humano: as origens da constituição cultural da criança na perspectiva deLev S. Vigotski. 1. ed. São Paulo: Cortez, 2005. 
ARAÚJO,C.C.M.;LACERDA,C.B.F.

VYGOTSKY, L.S. Teoria emétodo em psicologia. 1. ed. São Paulo: Martins Fontes, 1996 [original de 1926].

Pensamento e linguagem. 3. ed. São Paulo: Martins Fontes, 2005 [publicado postumamenteem 1934].

. A formação social da mente. 2. ed. São Paulo: Martins Fontes, 1998 [org. COLE, M. et al . - textos originais de diferentes datas].

. LURIA, A.R.; LEONTIEV, A.N. Linguagem, desenvol vimento eaprendizagem. 3. ed. São Paulo: Ícone/ Edusp, 1988 [original de 1930].

WERTSCH, J.V.; HICKMANN, M. Problem solving in social interaction: a microgenetic analysis. In: HICKMAN N, M. (Org). Social and functional approaches tolanguageand thought. 1. ed. N ova York: A cademic Press, 1987.

Recebido em 24/ 03/ 2008

Reformulado em 15/ 09/ 2008

A provado em 04/ 12/ 2008 